\title{
FRACTURE INITIATION AND PROPAGATION IN IN-SITU TIAI MATRIX COMPOSITE REINFORCED WITH CARBIDE PARTICLES
}

\author{
Tatiana PELACHOVÁ, Juraj LAPIN \\ Institute of Materials and Machine Mechanics, Slovak Academy of Sciences, Bratislava, \\ Slovak Republic, EU, tatiana.pelachova@savba.sk
}

https://doi.org/10.37904/metal.2019.751

\begin{abstract}
The fracture initiation and propagation was studied in a novel in-situ Ti-44.5Al-8Nb-4.8C-0.8Mo-0.1B (at\%) composite reinforced with carbide particles. The composite was prepared by vacuum induction melting in graphite crucibles and precise casting into graphite mould. The as-cast samples were subjected to hot isostatic pressing and stabilisation annealing. The phase composition of the test specimens was characterised by Xray diffraction analysis and transmission electron microscopy. The fracture of the composite was studied by scanning electron microscopy (SEM) and SEM in backscattered mode (BSEM). The coarse primary carbide particles are found to be effective obstacles to propagation of cracks initiated in the TiAl matrix during roomtemperature three point bending test. The propagation of fracture in the in-situ composite includes crack arrest by carbide particles, crack deflection, delamination on the matrix-carbide interfaces and extraction of some carbide reinforcements from the TiAl matrix.
\end{abstract}

Keywords: TiAl, carbide particles, composites, three-point bending test, fracture behavior

\section{INTRODUCTION}

An effort to improve the high temperature properties and room temperature ductility of TiAl alloys led to the development of TiAl based composites reinforced by carbide particles. Coarse primary particles of $\mathrm{H}-\mathrm{Ti}_{2} \mathrm{AIC}$ phase form in these composites during casting and fine secondary needle-like $\mathrm{P}-\mathrm{Ti}_{3} \mathrm{AIC}$ and plate-like $\mathrm{H}-\mathrm{Ti}_{2} \mathrm{AIC}$ precipitates during ageing or heat treatment [1-14]. Improvement of the fracture toughness of the in-situ TiAI based composites depends on applied processing techniques, size and volume fraction of carbide particles [1-8]. In general, increase of the fracture resistance of TiAl based composites in comparison to the single phase TiAl is attributed to crack trapping and crack bridging mechanisms by carbide particles [12]. With the increase of carbon content, the volume fraction of carbide particles increases and carbides can form clusters, which can negativelly affect the mechanical behavior of the in-situ composites [7]. Moreover, as a result of carbon increase, primary $\mathrm{H}-\mathrm{Ti}_{2} \mathrm{AIC}$ particles of different morphology can form in TiAl matrix [1-2]. In spite of previous studies on in-situ composites, there is lack of information about the effect of carbide particles with various morphology on initiation and crack propagation during room temperature mechanical loading.

The aim of this work is to study fracture initiation and propagation in in-situ composite with nominal composition Ti-44.5Al-8Nb-4.8C-0.8Mo-0.1B (at\%) during room temperature three-point bending tests. Carbide particles of different shape and size were formed in the composite during casting and subsequent heat treatment. The fractography analysis of the in-situ composite is also supported by TEM observations.

\section{EXPERIMENT}

Samples of in-situ composite with nominal composition Ti-44.5Al-8Nb-4.8C-0.8Mo-0.1B (at\%) were prepared by vacuum induction melting and centrifugal casting [2]. After casting, the as-cast composite was subjected to heat treatments consisting of hot isostatic pressing (HIP) at a temperature of $1250^{\circ} \mathrm{C}$ and applied pressure of $200 \mathrm{MPa}$ for $4 \mathrm{~h}$ in argon, followed by annealing at $900{ }^{\circ} \mathrm{C}$ for $25 \mathrm{~h}$ in air. 
Room temperature three-point bending (3PB) tests were carried out using V-notch specimens with a thickness of $10 \mathrm{~mm}$, width of $10 \mathrm{~mm}$, length of $55 \mathrm{~mm}$, notch length of $2 \mathrm{~mm}$ and notch tip radius of $0.25 \mathrm{~mm}$ at a cross head speed of $0.5 \mathrm{~mm} / \mathrm{min}$. The specimens were prepared by wire electrical discharge machining and grinding from the heat treated (HT) in-situ composite.

Microstructure and fractography analyses of the samples were carried out by scanning electron microscopy using secondary electron (SEM) or back scattered electron (BSE) detectors. Phase characterization of the studied in-situ composite was performed by X-ray diffraction (XRD) and transmission electron microscopy (TEM). Samples for SEM were etched in a reagent of $150 \mathrm{ml} \mathrm{H} 2 \mathrm{O}, 25 \mathrm{ml} \mathrm{HNO}_{3}$ and $10 \mathrm{ml} \mathrm{HF}$. The samples for TEM were mechanically thinned up to a thickness for about $40-50 \mu \mathrm{m}$ and subsequently finalized by ion milling until perforation using GATAN PIPS II machine. TEM observations were performed on JEOL1200 FX microscope operated at $100 \mathrm{kV}$. Volume fraction and size of coexisting phases were determined from digitalized BSE micrographs using a computer image analyser.

\section{RESULTS AND DISCUSSION}

\subsection{Microstructure evaluation of the composite}

Figure 1 shows XRD diffraction pattern of the HT in-situ composite. Two phase microstructure is composed of tetragonal $\gamma(\mathrm{TiAl})$ phase and remaining diffraction peaks belong to the hexagonal $\mathrm{H}-\mathrm{Ti}_{2} \mathrm{AlC}$ phase. Figure 2 shows BSE micrographs of the studied HT in-situ composite. A relatively uniform distribution of the coarse primary carbide particles of different morphology is formed within the $\gamma$ matrix, as seen in Figure $\mathbf{2 a}$. Figure $\mathbf{2 b}$ shows enlarged detail of the microstructure (blue rectangle in Figure 2a) with primary carbide particles.

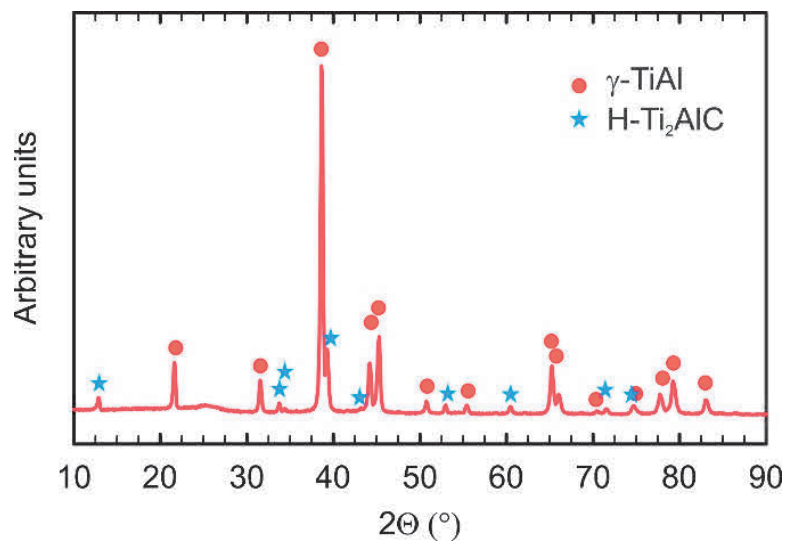

Figure 1 XRD diffraction pattern of $\mathrm{HT}$ in-situ composite Volume fraction of these carbide particles is measured to be $(20.0 \pm 0.5)$ vol\%. Some coarse $\mathrm{Ti}_{2} \mathrm{AIC}$ particles contain untransformed TiC phase in their cores. The matrix of the composite is not fully homogenized and is composed of dendritic $\gamma$ phase enriched by $\mathrm{Nb}$ and $\mathrm{Ti}$ (bright colour phase) and interdendritic $\gamma_{i}$ enriched by Al (grey colour phase).

Figure 3 shows TEM micrographs of the in-situ composite. The $\gamma$ matrix is found in the form of lamellar or single-phase grains of different size, as seen in Figure 3a. The interdendritic $\gamma_{i}$ corresponds to the area with the single-phase $\gamma$ grains. The large $\gamma$ grain is surrounded by numerous smaller $\gamma$ grains with a size of about $2.3 \mu \mathrm{m}$. Some of these grains contain few coarse lamellae with some secondary precipitates or the lamellar interfaces are enclosed by dislocation walls. The dendritic area is predominantly composed of lamellar $\gamma / \gamma$ grains with secondary precipitates on lamellar interfaces and grain boundaries. Besides the large coarse primary carbides, the in-situ composite contains smaller particles with a size not exceeding $2 \mu \mathrm{m}$. Figure $\mathbf{3 b}$ shows TEM micrograph of such small primary $\mathrm{H}-\mathrm{Ti}_{2} \mathrm{AlC}$ particle with its corresponding selected area diffraction (SAD) pattern. The crystallographic orientation relationship between such carbide particles and surrounding $\gamma$ grains is found to be random. During the heat treatment the fine secondary carbides precipitate preferentially within the coarse $\gamma$ grains and along the $\gamma$ grain boundaries and the $\gamma / \gamma$ lamellar interfaces. Figure $3 \mathbf{c}$ shows the area with small $\gamma$ grains surrounded by numerous fine particles formed along their boundaries. These particles were identified to belong to $\mathrm{H}-\mathrm{Ti}_{2} \mathrm{AlC}$ phase, as shown in inset of the Figure $3 c$. 

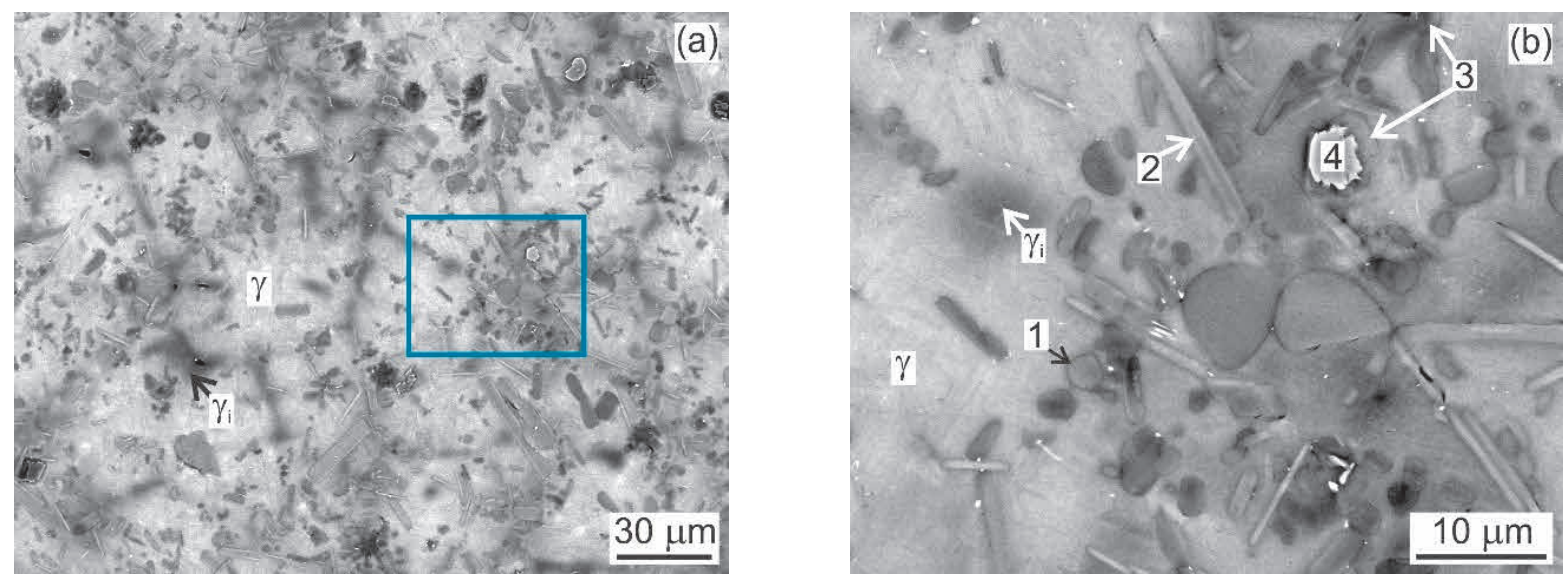

Figure 2 BSE micrographs showing microstructure of HT in-situ composite: (a) Distribution and morphology of coarse primary carbide particles in the matrix composed of dendritic $\gamma$ and interdendritic $\gamma_{i}$; (b) Enlarged detail showing the morphology of coarse primary $\mathrm{H}-\mathrm{Ti}_{2} \mathrm{AlC}$ particles of regular (1), plate-like (2) and irregular shape (3) with some remaining TiC (4)
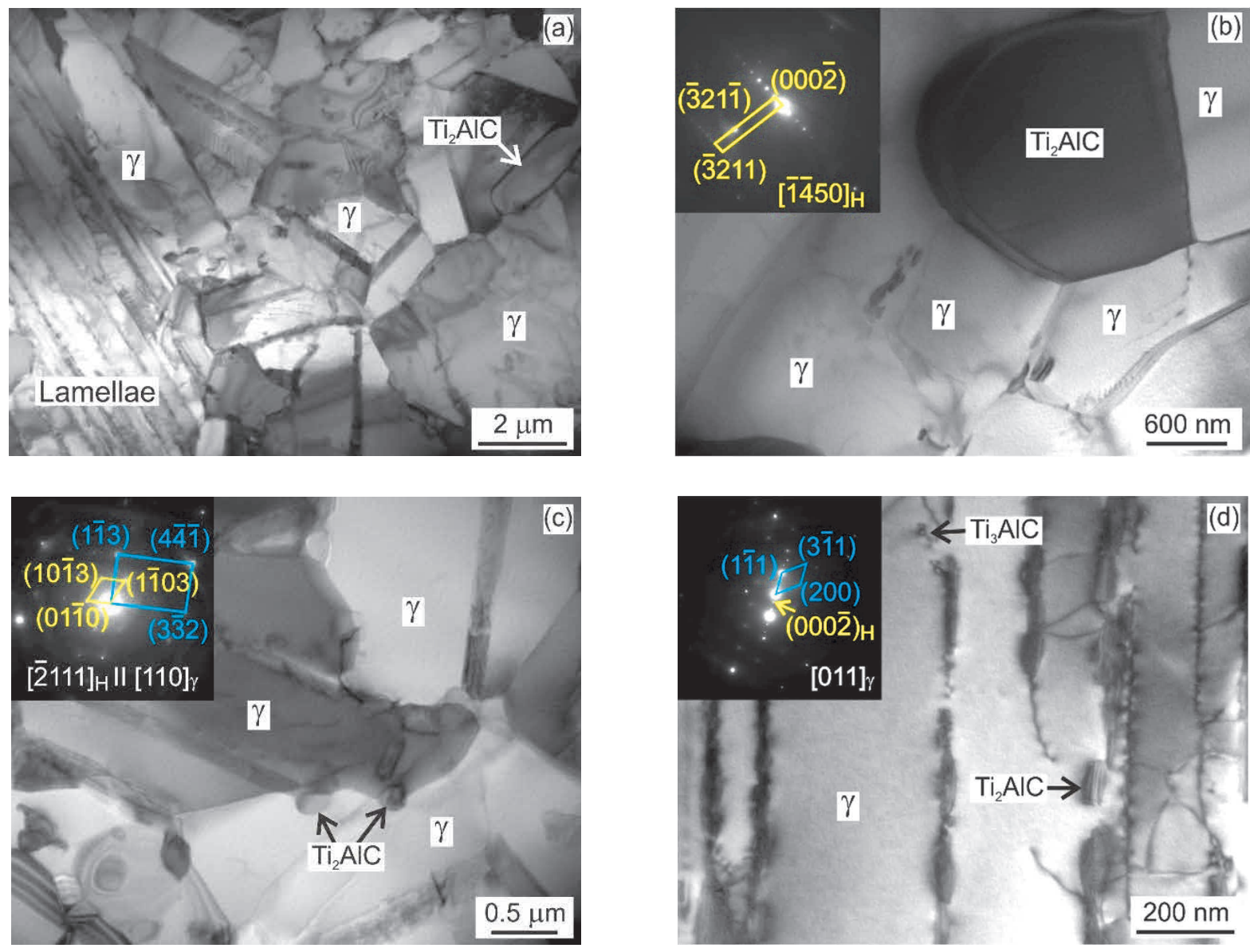

Figure 3 TEM micrographs showing microstructure of HT in-situ composite: (a) Primary $\mathrm{H}$-Ti2 $\mathrm{AIC}$ particle in the matrix composed of single-phase $\gamma$ and lamellar $\gamma / \gamma$ grains; (b) Primary $\mathrm{H}-\mathrm{Ti}_{2} \mathrm{AIC}$ particle embedded in small recrystallized $\gamma$ grains; (c) Distribution of secondary $\mathrm{H}-\mathrm{Ti}_{2} \mathrm{AIC}$ precipitates along $\gamma$ grain boundaries; (d) Secondary $\mathrm{H}-\mathrm{Ti}{ }_{2} \mathrm{AIC}$ and $\mathrm{P}-\mathrm{Ti}_{3} \mathrm{AIC}$ precipitates within the lamellar $\gamma / \gamma$ grains 
Figure 3d shows detail of the lamellar $\gamma / \gamma$ area where two kinds of secondary precipitates can be observed. The diffraction pattern along the $(1 \overline{1} 1)$ planes of the $\gamma$ phase indicates the existence of some weak reflections corresponding to (0002) planes of the $\mathrm{H}-\mathrm{Ti}_{2} \mathrm{AlC}$ phase. Besides the secondary $\mathrm{H}-\mathrm{Ti}_{2} \mathrm{AlC}$ precipitates, fine P$\mathrm{Ti}_{3} \mathrm{AIC}$ precipitates can be identified within the lamellar $\gamma / \gamma$ grains [2]. The coexistence of secondary $\mathrm{P}-\mathrm{Ti}_{3} \mathrm{AIC}$ and $\mathrm{H}-\mathrm{Ti}_{2} \mathrm{AlC}$ precipitates was reported also by several authors $[8,10]$ in the microstructure of Ti-46Al-8Nb(1.4-2.5)C and Ti-45Al-5Nb-(0.75-1)C alloys.

\subsection{Fracture initiation and propagation during room temperature three-point bending tests}

Figure 4 shows crack initiation and propagation in the insitu composite after interrupted 3PB test. The crack is initiated in the vicinity of the notch tip and propagates in direction opposite to the load direction. Figure $\mathbf{5}$ shows propagation of the main crack and distribution of the secondary short cracks in the composite. Numerous fine side cracks are observed in the vicinity of the main crack. These cracks are initiated at the $\gamma$ grain boundaries or interfaces of $\gamma$ phase with $\mathrm{H}-\mathrm{Ti}{ }_{2} \mathrm{AlC}$ particles, but then they propagate through the grains, as seen in Figure $\mathbf{5 a}$. The

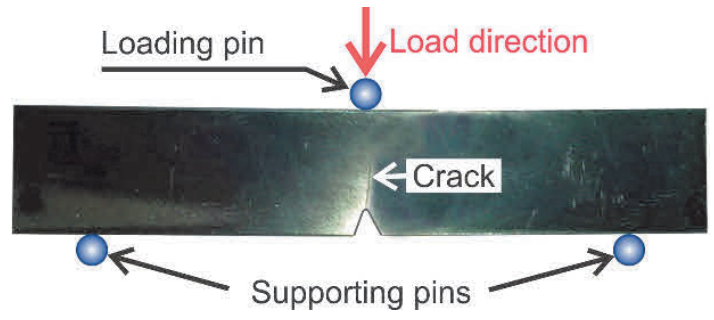

Figure 4 Initiation of crack during 3PB test with schematic depiction of test arrangement primary $\mathrm{H}-\mathrm{Ti}_{2} \mathrm{AlC}$ particles can effectively deflect these cracks during loading. Figure $\mathbf{5 b}$ shows the area of the composite where the main crack is stopped by primary $\mathrm{H}-\mathrm{Ti}_{2} \mathrm{AlC}$ particles. The zigzag propagation of the main crack results from its interactions with the grain boundaries and coarse primary carbide particles. The effectiveness of the $\mathrm{H}-\mathrm{Ti}_{2} \mathrm{AlC}$ particles to hinder crack propagation depends strongly on their crystallographic orientation to the load direction [15]. The crack propagates frequently along the interfaces of favorably oriented particles with the matrix as well as through the carbide particles bridging the crack. Figure 6 shows fracture surface of the in-situ composite. The pull-out of the coarse $\mathrm{H}-\mathrm{Ti}_{2} \mathrm{AIC}$ particles, decohesion along the matrix/carbide particle interfaces, crack deflection, laminated tearing and delamination of the carbides can be well identified on the fracture surface, as shown in Figure $6 \mathbf{a}$. The pull-out of the carbide particles from the matrix increases the fracture energy of the TiAl matrix [12]. The observed laminated tearing and the kinking boundaries of the $\mathrm{H}-\mathrm{Ti}{ }_{2} \mathrm{AlC}$ particles confirm that the reinforcing phase contributes to the fracture toughness and damage tolerance of the in-situ composite
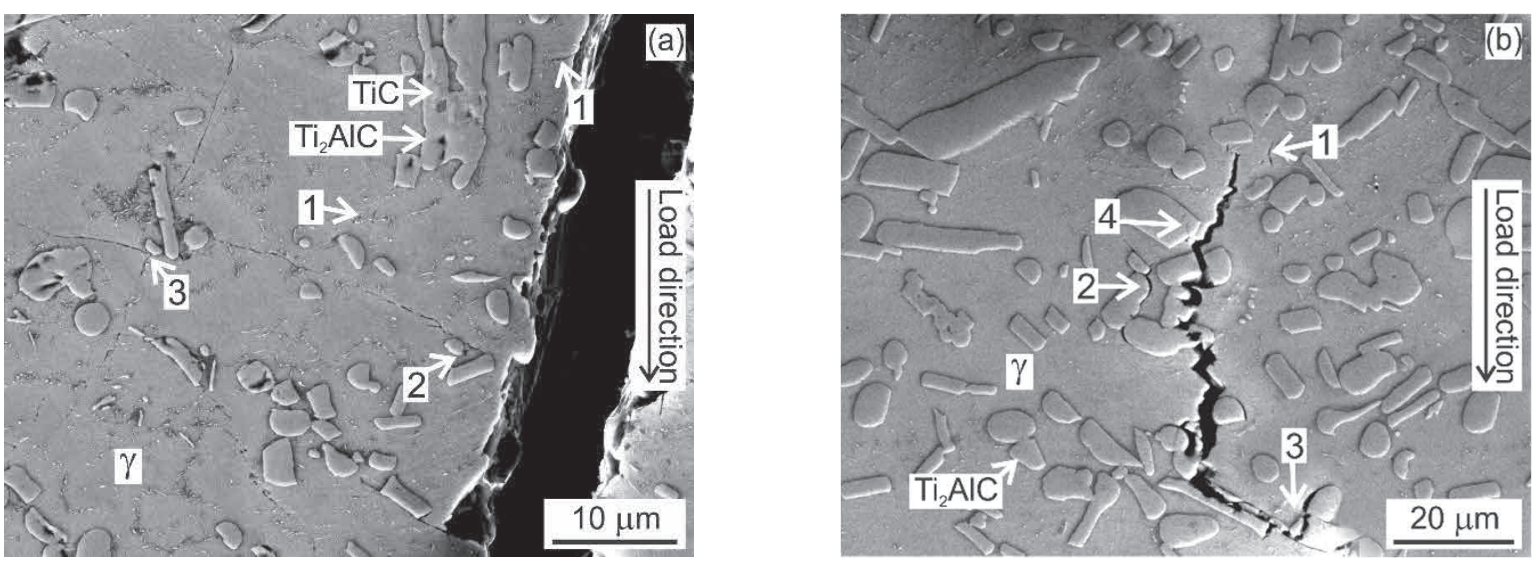

Figure 5 SEM micrographs showing initiation, propagation and crack arrest in in-situ composite:

(a) Nucleation of short cracks in the vicinity of the main crack; (b) Zigzag crack propagation and crack arrest

by the primary $\mathrm{H}-\mathrm{Ti}_{2} \mathrm{AIC}$ particles. 1 - crack initiation on the grain boundary, 2 - crack initiation at matrix/carbide interfaces, 3 - deflection of the cracks, 4 - delamination of the primary $\mathrm{H}$-Ti ${ }_{2} \mathrm{AIC}$ particles 

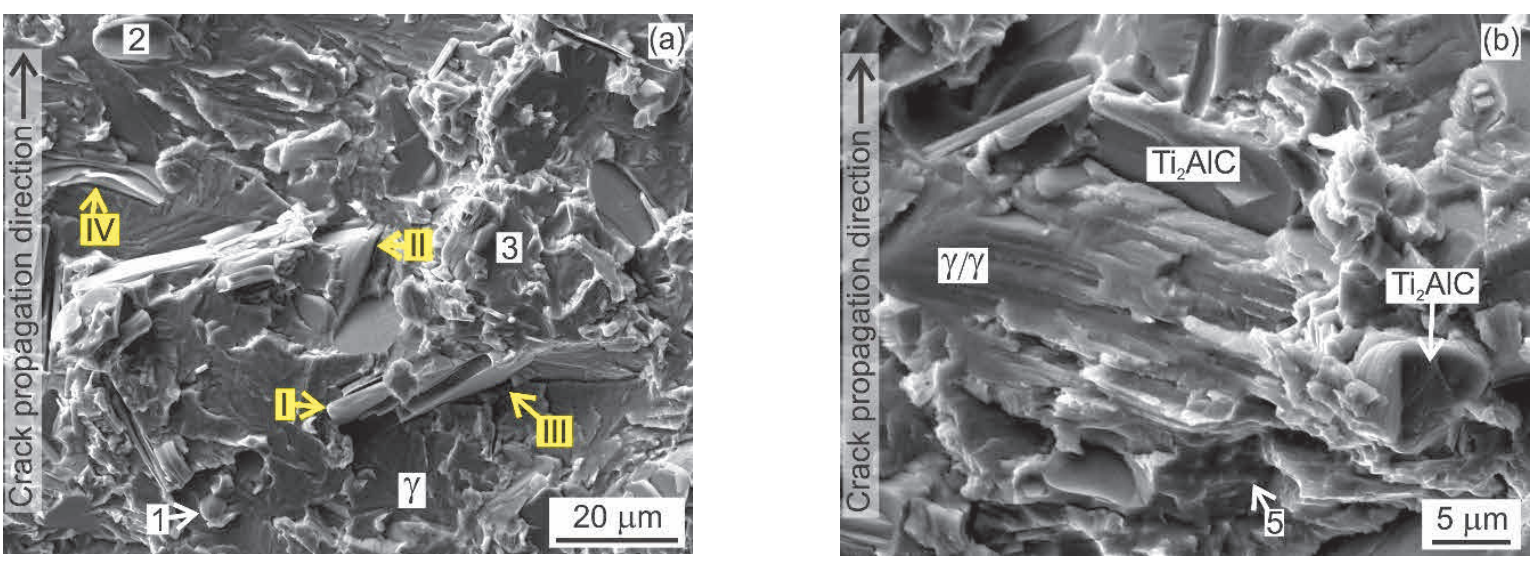

Figure 6 Fracture surface of in-situ composite: (a) Fracture mode of $\mathrm{H}-\mathrm{Ti}_{2} \mathrm{AlC}$ particles of regular (1), plate-

like (2) and irregular shape (3); (b) Fracture mode of lamellar $\gamma / \gamma$ grains and $\gamma$ grain boundaries with fine secondary carbide particles. (I) pull-out of $\mathrm{H}-\mathrm{Ti}_{2} \mathrm{AIC}$, (II) decohesion along particle/matrix interface, (III) crack deflection by carbide particle, (IV) laminated tearing and delamination of the carbides, (5) secondary carbide particles on the $\gamma$ grain boundary

when compared to those of single TiAl matrix. Moreover, the $\mathrm{H}-\mathrm{Ti}_{2} \mathrm{AIC}$ particles can retard crack propagation, which is manifested by the crack deflection. In the case of regular shaped carbide particles the crack is initiated at the particle/matrix interfaces. The fracture behavior of the irregular particles depends on their crystallographic orientation to the load direction and its fracture surface shows the same behavior like platelike $\mathrm{H}-\mathrm{Ti}_{2} \mathrm{AIC}$ particles. The TiC phase preserved in the core of some $\mathrm{H}-\mathrm{Ti}_{2} \mathrm{AIC}$ particles retards the crack propagation and causes the crack deflection. Song et al. [14] observed also crack deflection caused by TiC particles embedded in $\mathrm{H}-\mathrm{Ti}_{2} \mathrm{AlC}$ phase of TiAl/ $\mathrm{Ti}_{2} \mathrm{AlC}$ composite with $15 \mathrm{~mol} \%$ of $\mathrm{H}-\mathrm{Ti}_{2} \mathrm{AlC}$ addition. Figure $\mathbf{6 b}$ shows the fracture surface through lamellar $\gamma / \gamma$ grain and along $\gamma$ grain boundaries containing numerous fine secondary carbide particles. The secondary $\mathrm{H}-\mathrm{Ti}_{2} \mathrm{AIC}$ and $\mathrm{P}-\mathrm{Ti}_{3} \mathrm{AIC}$ particles contribute to the strengthening of the composite. The cracks within the lamellar grains propagate along the $\gamma / \gamma$ lamellar interfaces as well as through the lamellar interfaces forming palisade type of fracture.

\section{CONCLUSION}

The fracture initiation and propagation in the in-situ Ti-44.5Al-8Nb-4.8C-0.8Mo-0.1B (at\%) composite reinforced with carbide particles was studied during room-temperature three point bending tests. The achieved results that can be summarized as follows:

- $\quad$ The microstrucure of the test samples before 3PB tests is composed of $\gamma(\mathrm{TiAl})$ matrix and primary and $\mathrm{H}-\mathrm{Ti}_{2} \mathrm{AlC}$ particles. Besides the primary carbide particles, the composite is reinforced with fine secondary $\mathrm{H}-\mathrm{Ti}_{2} \mathrm{AIC}$ and $\mathrm{P}-\mathrm{Ti}{ }_{3} \mathrm{AIC}$ precipitates formed during the heat treatment.

- $\quad$ The coarse primary $\mathrm{H}-\mathrm{Ti}_{2} \mathrm{AIC}$ particles are found to serve as the effective obstacles to crack propagation. Primary plate-like and irregular shaped $\mathrm{H}-\mathrm{Ti}_{2} \mathrm{AIC}$ particles and their distribution have the key effect on the initiation and crack propagation.

- The fracture of the in-situ composite includes crack arrest, pull-out of the coarse $\mathrm{H}-\mathrm{Ti}_{2} \mathrm{AlC}$ particles, decohesion at the matrix/particle interfaces, crack deflection, laminated tearing and delamination of the carbide reinforcements.

\section{ACKNOWLEDGEMENTS}

This work was financially supported by the Slovak Research and Development Agency under the contract APVV-15-0660. 


\section{REFERENCES}

[1] ŠTAMBORSKÁ, Michaela, LAPIN, Juraj and BAJANA, Oto. Effect of carbon on the room temperature compressive behaviour of Ti-44.5Al-8Nb-0.8Mo- $x \mathrm{C}$ alloys prepared by vacuum induction melting. Kovové Materiály - Metallic Materials. 2018. vol. 56, no. 6, pp. 349-356.

[2] LAPIN, Juraj, ŠTAMBORSKÁ, Michaela, KAMYSHNYKOVA, Kateryna, PELACHOVÁ, Tatiana, KLIMOVÁ, Alena and BAJANA, Oto. Room temperature mechanical behaviour of cast in-situ TiAl matrix composite reinforced with carbide particles. Intermetallics. 2019. vol. 105, pp. 113-123.

[3] ČEGAN, Tomáš and SZURMAN Ivo. Thermal stability and precipitation strengthening of fully lamellar Ti-45AI5Nb-0.2B-0.75C. Kovové Materiály - Metallic Materials. 2017. vol. 55, no. 2, pp. 421-430.

[4] SONG, Xiao-Jie, CUI, Hong-Zhi, HOU, Nan, WEI, Na, HAN, Ye, TIAN, Jian and SONG, Qiang. Lamellar structure and effect of Ti2AIC on properties of prepared in-situ TiAl matrix composites. Ceramics International. 2016. vol. 42, no. 12, pp. 13586-13592.

[5] CHEN, Ruirun, FANG, Hongze, CHEN, Xiaoyu, SU, Yanqing, DING, Hongsheng, GUO, Jingjie and FU, Hengzhi. Formation of $\mathrm{TiC} / \mathrm{Ti}_{2} \mathrm{AlC}$ and $\alpha_{2}+\gamma$ in in-situ TiAl composites with different solidification paths. Intermetallics. 2017. vol. 81, pp. 9-15.

[6] YANG, Chen-Hui, WANG, Fen, Al, Tao-Tao and ZHU, Jian-Feng. Microstructure and mechanical properties of in situ TiAl/Ti2AlC composites prepared by reactive hot pressing. Ceramics International. 2014. vol. 40, no. 6, pp. 8165-8171.

[7] KAMYSHNYKOVA, Kateryna and LAPIN, Juraj. Grain refinement of cast peritectic TiAl-based alloy by solid-state phase transformations. Kovové Materiály - Metallic Materials. 2018. vol. 56, no. 5, pp. 277-287.

[8] WU, Zeen, HU, Rui, ZHANG, Tiebang, ZHANG, Fan, KOU, Hongchao and LI, Jinshan. Understanding the role of carbon atoms on microstructure and phase transformation of high $\mathrm{Nb}$ containing TiAl alloys. Materials Characterization. 2017. vol. 124, pp. 1-7.

[9] WANG, Li, ZENK, Carolin, STARK, Andreas, FELFER, Peter, GABRISCH, Heike, GÖKEN, Mathias, LORENZ, Uwe and PYCZAK, Florian. Morphology evolution of Ti 3 AIC carbide precipitates in high Nb containing TiAl alloys. Acta Materialia. 2017. vol. 137, pp. 36-44.

[10] GABRISCH, Heike, STARK, Andreas, SCHIMANSKY, Frank-Peter, WANG, Li, SCHELL, Norbert, LORENZ, Uwe and PYCZAK, Florian. Investigation of carbides in Ti-45Al-5Nb- $x$ C alloys $(0 \leq x \leq 1)$ by transmission electron microscopy and high energy-XRD. Intermetallics. 2013. vol. 33, pp. 44-53.

[11] VANKATESWARA RAO, K.T., ODETTE, G.R. and RITCHIE, R.O. Ductile-reinforcement toughening in $\gamma$-TiAl intermetallic-matrix composites: effects on fracture toughness and fatigue-crack propagation. Acta Metallurgica \& Materialia. 1994. vol. 42, pp. 893-911.

[12] CAO, R., LEI, M.X., CHEN, J.H. and ZHANG, J. Effects of loading rate on damage and fracture behavior of TiAl alloys. Materials Science\&Engineering A-Structural Materials Properties and Microstructure and Processing. 2007. vol. A465, pp. 183-193.

[13] WANG, Li, GABRISCH, Heike, LORENZ, Uwe, SCHIMANSKY, Frank-Peter, SCHREYER, Andreas, STARK, Andreas and PYCZAK, Florian. Nucleation and thermal stability of carbide precipitates in high $\mathrm{Nb}$ containing TiAl alloys. Intermetallics. 2015. vol. 66, pp. 111-119.

[14] SONG, Xiao-Jie, CUI, Hong-Zhi, HAN, Ye, HOU, Nan, WEI, Na, DING, Lei and SONG, Qiang. Effect of carbon reactant on microstructures and mechanical properties of TiAl/Ti ${ }_{2} \mathrm{AlC}$ composites. Materials

Science\&Engineering A-Structural Materials Properties and Microstructure and Processing. 2017. vol. A684, pp. 406-412.

[15] YANG, H.J., PEI, Y.T., SONG, G.M. and DE HOSSON, J.Th.M. Healing performance of $\mathrm{Ti}_{2} \mathrm{AIC}$ ceramic studied with in situ microcantilever bending. Journal of the European Ceramic Society. 2013. vol. 33, pp. 383-391. 